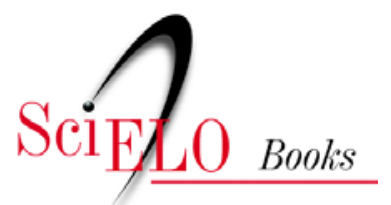

\title{
2 - Dinâmica dos investimentos no mundo e no Brasil
}

\author{
Carlos A. Grabois Gadelha (cood.)
}

\section{SciELO Books / SciELO Livros / SciELO Libros}

GADELHA, CAG., cood. Dinâmica dos investimentos no mundo e no Brasil. In: A dinâmica do sistema produtivo da saúde: inovação e complexo econômico-industrial [online]. Rio de Janeiro: Editora FIOCRUZ, 2012, pp. 21-40. ISBN: 978-85-7541-593-1. Available from: doi: 10.7476/9788575415931.0003. Also available in ePUB from: http://books.scielo.org/id/6t3hs/epub/gadelha-9788575415931.epub

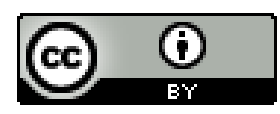

All the contents of this work, except where otherwise noted, is licensed under a Creative Commons Attribution 4.0 International license.

Todo o conteúdo deste trabalho, exceto quando houver ressalva, é publicado sob a licença Creative Commons Atribição 4.0. 


\section{2 \\ Dinâmica dos Investimentos no Mundo e no Brasil}

Neste capítulo, procura-se apreender a dinâmica sistêmica do Complexo EconômicoIndustrial da Saúde (CEIS) em seu conjunto, uma vez que os subsistemas serão trabalhados em capítulos específicos e, portanto, mais abrangentes. $\mathrm{O}$ ponto de partida para a análise da dinâmica de investimentos em saúde é o modelo político-institucional que vigora nos Estados nacionais e organiza os sistemas de saúde, compondo o mix público-privado e a relação entre o financiamento público e os recursos de natureza privada. Os sistemas nacionais de saúde constituem-se a partir de um processo de pactuação política que foi uma das grandes bases da conformação dos Estados de bemestar ao longo do pós-guerra, revelando, talvez mais do que em qualquer outra área, a natureza política e institucional da organização dos mercados. Conformam, assim, o ambiente concreto em termos de tempo e espaço em que o sistema produtivo e de inovação em saúde está imerso, condicionando as estratégias nacionais e empresariais de investimento nos segmentos envolvidos nesta produção.

Quase todos os países da Organização para a Cooperação e Desenvolvimento Econômico (OCDE) contam com sistemas públicos de saúde abrangentes e articulados com um conjunto regulado de prestadores de serviços, submetidos a políticas, programas e atividades majoritariamente financiadas pelo Estado. Vários modelos se baseiam, ainda que não exclusivamente, na arrecadação geral de impostos, como os vigentes no Canadá, na Suécia, no Reino Unido, na Espanha e em Portugal, entre outros. Alemanha e França sustentam seus modelos públicos de saúde com base essencialmente nas contribuições de empresas e empregados. Em muitos casos, em complemento ao financiamento público assumem-se suplementações no financiamento com despesas diretas dos usuários, seja na forma de copagamentos, despesas não cobertas ou mesmo para se evitar filas de espera e garantir a livre escolha, entre outros benefícios não assegurados no sistema público. 
Os Estados Unidos, por sua vez, têm o sistema mais típico de mercado, majoritariamente na forma de seguros médicos, assumidos por empregadores ou autonomamente pelos indivíduos ou ainda por grupos de indivíduos. Observe-se que há modelos de seguros com financiamento público para populações específicas, como idosos e grupos de baixa renda. Nos últimos anos, como ficou claro no debate eleitoral de 2008 e no programa de governo do presidente Barack Obama, reconhecese amplamente o caráter excludente, ineficiente e caro desse sistema em comparação com os sistemas europeus, os quais conferem alta prioridade política ao acesso universal à saúde.

A Figura 4 sintetiza os modelos básicos de financiamento da saúde em países específicos, permitindo, de modo genérico, reter a estilização feita na literatura da área e indicar a existência de três grandes modelos de organização histórica do sistema de saúde: os universais, que têm na Inglaterra e no Canadá exemplos clássicos; os corporativos, associados às relações de trabalho, sendo a Alemanha o exemplo destacado; os de mercado, sendo os EUA o caso típico (Giovanella et al., 2008). Mesmo nas experiências dos sistemas universais europeus, observa-se um processo de garantia do direito à saúde mediante a 'desmercantilização' da demanda convivendo com uma oferta empresarial mercantil em todos os segmentos do complexo (Viana \& Elias, 2007). Tal convivência indica a necessidade, inerente à área da saúde, de articulação, implícita ou explícita, entre o Estado e o setor produtivo nos processos de investimento.

A Tabela 1 mostra que na maior parte dos países da OCDE o gasto público responde por parte amplamente majoritária do gasto total em saúde (ou seja, do "mercado da saúde"), com uma participação média de $71 \%$, sendo que nos sistemas mais universais tal gasto responde por aproximadamente $80 \%$, chegando a quase 84\% no Reino Unido, para dar um exemplo destacado. O Estado representa parcela minoritária do gasto em saúde - mesmo que acima de $45 \%$ - apenas nos EUA, no México e no Chile.

No Mercado Comum do Sul (Mercosul), a situação se inverte: mesmo considerada a menor renda destes países, o esforço público em relação ao gasto privado mostra-se bastante reduzido, quase nos patamares dos sistemas não universais, tendo o Estado uma participação média de $55,6 \%$ no total das despesas com saúde.

Nesse contexto, o caso brasileiro se mostra bastante peculiar. Por um lado, o país tem um perfil de gasto típico de um sistema em que a saúde não é vista como um bem público - situando-se abaixo dos 50\% dos gastos totais. No tocante às contas nacionais, dados do Instituto Brasileiro de Geografia e Estatística (IBGE, 2012a) indicam uma situação ainda mais precária, com as famílias respondendo por 55\% do consumo final em saúde, enquanto a Administração Pública responde por apenas $44 \%^{4}$ (ver cap. 6), o que se mostra mais grave quando se considera a baixa renda per capita do país em relação aos países da OCDE. A Tabela 2, por sua vez, ressalta que,

${ }^{4} \mathrm{O}$ ponto percentual restante refere-se à participação das instituições sem fins lucrativos. 
mesmo comparando-se o esforço dos Estados nacionais da OCDE e do Mercosul em conjunto, o Brasil é, dentre todos os países contemplados, aquele em que o gasto público em saúde é o menor em relação à despesa pública total, e substancialmente inferior mesmo quando comparado ao dos países menos desenvolvidos do Mercosul, como o Paraguai. Ressalve-se que essa participação tem crescido desde o ano 2000. No bloco dos países menos desenvolvidos e dos emergentes, aqueles de grande porte territorial e populacional e com estruturas produtivas complexas e diversificadas Brasil, Rússia, Índia e China (Brics) -, o Brasil situa-se em uma posição intermediária quanto ao perfil de demanda, juntando-se, neste caso, a países cujos sistemas apresentam grandes problemas de acesso e de exclusão, como a China e a Índia.

Por outro lado, e de modo contraditório, a Constituição brasileira de 1988 definiu que a saúde é um direito do cidadão e um dever do Estado, como desdobramento de um pacto político e social para a criação de um sistema universal de saúde, com os seguintes princípios:

- Universalidade: garantia de acesso de todos aos bens e serviços de saúde, independentemente de vínculo empregatício e de posição social;

- Integralidade: garantia de acesso de todos os cidadãos aos bens e serviços que atendam às necessidades de saúde, independentemente da complexidade tecnológica;

- Equidade: acesso equânime de todo cidadão aos bens e serviços de saúde, independentemente do nível de renda e da região e local em que se vive.

Esses princípios constitucionais são cruciais para se pensar o sistema produtivo da saúde e fornecem o marco geral para uma análise em que se torna inescapável uma abordagem pautada pela economia política. É nessa perspectiva, que remete a um determinado padrão de desenvolvimento, que se devem desenhar os quadros de referência prospectiva para os investimentos. Nesses termos, os cenários não apenas refletem a perspectiva isenta do pesquisador, mas também são resultado de uma visão política que toma os princípios constitucionais como marco de referência para se avaliar e sugerir diretrizes e estratégias.

Observa-se clara inconsistência entre o gasto em saúde e sua distribuição no Brasil e a conformação de um sistema universal, o que implica a necessidade tanto de um acentuado aumento do financiamento público dos serviços de saúde quanto do fortalecimento da base produtiva nacional para o atendimento de demanda econômica decorrente da perspectiva de universalização.

Em suma, o ponto de partida para se captar a dinâmica dos investimentos no mundo e no Brasil é entender a configuração dos sistemas nacionais de saúde e o contexto do país em que se registra uma forte expansão do mercado e da produção em saúde, tomando-se como referência o pacto político e social vigente na área da saúde. Esse contexto de expansão, todavia, traz importantes desafios para o CEIS, pois está 
em curso um acentuado processo de transformação nos padrões de demanda, nos padrões tecnológicos e nas forças da concorrência e de regulação.

Figura 4 - Principais fontes de financiamento e participação da despesa pública em saúde. Países diversos - 2005
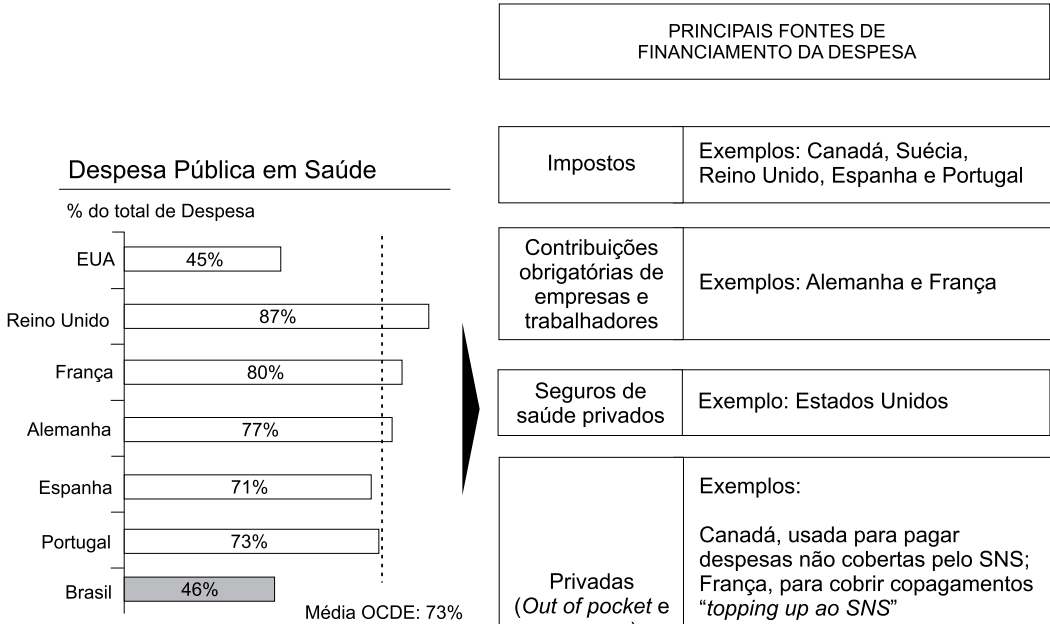

\begin{tabular}{|c|c|}
\hline $\begin{array}{c}\text { Seguros de } \\
\text { saúde privados }\end{array}$ & Exemplo: Estados Unidos \\
\hline
\end{tabular}

\begin{tabular}{|c|l|}
\hline \multicolumn{1}{|c|}{$\begin{array}{c}\text { Privadas } \\
\text { (Out of pocket e } \\
\text { seguros) }\end{array}$} & $\begin{array}{l}\text { Canadá, usada para pagar } \\
\text { despesas não cobertas pelo SNS; } \\
\text { França, para cobrir copagamentos } \\
\text { "topping up ao SNS" }\end{array}$ \\
$\begin{array}{l}\text { Espanha, Portugal e Reino Unido, } \\
\text { dupla cobertura para evitar listas } \\
\text { de espera e/ou garantir liberdade } \\
\text { de escolha }\end{array}$ \\
\hline
\end{tabular}

Fonte: Organization for Economic Co-Operation and Development, 2007.

Tabela 1 - Gastos públicos em saúde como \% do gasto total em saúde. OCDE e Mercosul - 2000-2009

\begin{tabular}{l|c|c|c|c|c|c|c|c|c|c}
\hline OCDE & 2000 & 2001 & 2002 & 2003 & 2004 & 2005 & 2006 & 2007 & 2008 & 2009 \\
\hline Canadá & 70,4 & 70,0 & 69,6 & 70,0 & 70,0 & 70,0 & 69,9 & 69,9 & 69,5 & 68,7 \\
\hline Méxic0 & 46,6 & 44,8 & 43,8 & 44,2 & 45,2 & 45,0 & 45,2 & 45,4 & 46,9 & 48,3 \\
\hline EUA & 43,7 & 44,2 & 44,1 & 45,0 & 45,4 & 45,5 & 46,4 & 46,8 & 47,8 & 48,6 \\
\hline Áustria & 76,8 & 76,1 & 75,8 & 75,5 & 75,7 & 76,1 & 73,3 & 73,3 & 73,7 & 74,5 \\
\hline Bélgica & 67,5 & 68,7 & 67,2 & 70,5 & 71,4 & 72,0 & 72,8 & 68,0 & 66,8 & 68,4 \\
\hline Dinamarca & 82,4 & 82,7 & 82,9 & 79,7 & 79,2 & 79,9 & 80,0 & 80,2 & 80,1 & 80,1 \\
\hline Finlândia & 71,1 & 71,8 & 72,3 & 68,3 & 69,0 & 69,5 & 70,2 & 70,2 & 70,7 & 72,1 \\
\hline França & 79,4 & 79,4 & 79,7 & 77,2 & 76,9 & 76,9 & 76,4 & 76,3 & 75,9 & 76,6 \\
\hline Alemanha & 79,8 & 79,3 & 79,3 & 76,1 & 74,4 & 74,3 & 74,4 & 74,5 & 74,6 & 75,7 \\
\hline Grécia & 60,0 & 60,8 & 58,0 & 59,8 & 59,1 & 60,1 & 62,0 & 60,3 & 60,9 & 62,6 \\
\hline Hungria & 70,7 & 69,0 & 70,2 & 69,9 & 69,2 & 69,7 & 69,7 & 67,7 & 68,9 & 69,6
\end{tabular}


Tabela 1 - Gastos públicos em saúde como \% do gasto total em saúde. OCDE e Mercosul - 2000-2009 (continuação)

\begin{tabular}{l|c|c|c|c|c|c|c|c|c|c}
\hline OCDE & 2000 & 2001 & 2002 & 2003 & 2004 & 2005 & 2006 & 2007 & 2008 & 2009 \\
\hline Islândia & 78,9 & 79,0 & 79,7 & 80,2 & 80,1 & 80,0 & 80,6 & 80,6 & 81,8 & 82,3 \\
\hline Irlanda & 75,3 & 76,1 & 76,4 & 76,4 & 77,0 & 76,6 & 76,3 & 76,8 & 76,9 & 79,6 \\
\hline Itália & 72,5 & 74,6 & 74,5 & 74,5 & 76,0 & 75,2 & 75,7 & 75,4 & 76,3 & 77,3 \\
\hline Japão & 81,3 & 81,7 & 81,5 & 78,6 & 79,4 & 80,4 & 79,4 & 80,3 & 80,5 & 80,0 \\
\hline Luxemburgo & 69,8 & 75,6 & 74,3 & 76,4 & 76,0 & 74,6 & 71,5 & 75,5 & 74,8 & 74,2 \\
\hline Holanda & 63,1 & 62,8 & 62,5 & 61,2 & 59,8 & 60,5 & 75,6 & 75,2 & 75,3 & 77,3 \\
\hline Noruega & 76,2 & 76,9 & 77,7 & 77,9 & 77,6 & 77,8 & 78,3 & 78,1 & 78,6 & 78,6 \\
\hline Polônia & 70,0 & 71,9 & 71,2 & 66,3 & 64,7 & 64,7 & 65,4 & 66,1 & 67,4 & 68,2 \\
\hline Portugal & 72,5 & 71,5 & 72,2 & 68,9 & 68,3 & 67,9 & 68,1 & 67,7 & 67,4 & 69,9 \\
\hline Espanha & 71,6 & 71,2 & 71,3 & 67,8 & 68,0 & 67,8 & 68,2 & 68,9 & 69,7 & 72,1 \\
\hline Suécia & 84,9 & 81,7 & 82,1 & 79,3 & 79,0 & 78,8 & 78,8 & 78,3 & 78,1 & 78,6 \\
\hline Suíça & 55,4 & 56,9 & 57,7 & 58,3 & 58,4 & 59,5 & 59,1 & 59,3 & 59,1 & 59,6 \\
\hline Turquia & 62,9 & 68,1 & 70,7 & 71,9 & 71,2 & 67,8 & 68,3 & 67,8 & 73,1 & 75,2 \\
\hline Reino Unido & 79,3 & 79,9 & 79,9 & 80,1 & 81,4 & 81,9 & 81,9 & 82,0 & 82,6 & 83,6 \\
\hline Austrália & 66,8 & 66,3 & 66,9 & 66,1 & 66,7 & 66,9 & 66,6 & 67,5 & 70,1 & 70,1 \\
\hline Nova Zelândia & 78,0 & 76,4 & 77,9 & 78,3 & 76,9 & 77,1 & 77,5 & 79,2 & 80,2 & 80,2 \\
\hline Coreia & 45,5 & 52,3 & 51,3 & 49,5 & 50,3 & 51,2 & 53,3 & 53,7 & 53,9 & 54,1 \\
\hline MÉDIA 0CDE & 69,7 & 70,3 & 70,4 & 69,6 & 69,5 & 69,6 & 70,2 & 70,2 & 70,8 & 71,6 \\
\hline & & & & & & & & \\
\hline
\end{tabular}

MERCOSUL

\begin{tabular}{l|l|l|l|l|l|l|l|l|l|l}
\hline Argentina & 55,4 & 54,2 & 53,6 & 52,3 & 52,3 & 54,2 & 55,8 & 59,4 & 62,6 & 66,4 \\
\hline BRASIL & 40,3 & 42,3 & 44,6 & 44,4 & 47,0 & 40,1 & 41,7 & 41,6 & 44,0 & 45,7 \\
\hline Paraguai & 40,1 & 35,0 & 34,6 & 34,3 & 37,1 & 40,4 & 39,2 & 41,4 & 40,1 & 42,9 \\
\hline Venezuela & 58,5 & 59,3 & 60,7 & 61,9 & 58,6 & 56,7 & 58,3 & 53,5 & 55,1 & 60,0 \\
\hline Uruguai & 54,6 & 54,0 & 53,2 & 50,8 & 49,3 & 50,2 & 52,9 & 54,5 & 63,1 & 63,1 \\
\hline MÉDIA MERCOSUL & 49,8 & 49,0 & 49,3 & 48,7 & 48,9 & 48,3 & 49,6 & 50,1 & 53,0 & 55,6 \\
\hline
\end{tabular}

Fonte: elaborada por GIS/Ensp/Fiocruz, com base em dados da WH0, 2010. 
Tabela 2 - Percentual do gasto total do governo nos gastos públicos em saúde. OCDE, Mercosul e Brics - 2000-2009

\begin{tabular}{|c|c|c|c|c|c|c|c|c|c|c|}
\hline OCDE & 2000 & 2001 & 2002 & 2003 & 2004 & 2005 & 2006 & 2007 & 2008 & 2009 \\
\hline Alemanha & 18,2 & 17,4 & 17,5 & 17,0 & 16,7 & 17,0 & 17,3 & 17,8 & 18,0 & 18,0 \\
\hline Austrália & 15,3 & 15,6 & 16,5 & 16,2 & 16,7 & 16,8 & 17,1 & 17,6 & 18,3 & 18,3 \\
\hline Áustria & 14,7 & 14,9 & 15,0 & 15,1 & 14,6 & 15,8 & 15,2 & 15,5 & 15,8 & 15,8 \\
\hline Bélgica & 12,3 & 12,7 & 12,5 & 13,9 & 15,2 & 14,2 & 14,9 & 15,1 & 14,8 & 14,8 \\
\hline Canadá & 15,1 & 15,5 & 16,2 & 18,1 & 17,5 & 16,7 & 16,9 & 17,1 & 17,2 & 17,0 \\
\hline Coréia & 9,7 & 11,6 & 11,2 & 9,2 & 10,4 & 11,0 & 11,7 & 11,9 & 12,3 & 12,3 \\
\hline Dinamarca & 12,6 & 13,1 & 13,2 & 13,3 & 13,6 & 14,1 & 14,9 & 15,3 & 15,3 & 15,3 \\
\hline Espanha & 13,2 & 13,3 & 13,4 & 14,4 & 14,3 & 14,6 & 14,9 & 14,8 & 15,2 & 15,2 \\
\hline EUA & 17,1 & 17,8 & 18,2 & 18,1 & 15,5 & 18,5 & 19,1 & 19,0 & 18,7 & 18,7 \\
\hline Finlândia & 10,6 & 11,1 & 11,5 & 11,1 & 11,4 & 11,7 & 12,0 & 12,2 & 12,6 & 12,6 \\
\hline França & 15,5 & 15,7 & 15,9 & 15,8 & 15,9 & 16,0 & 16,1 & 16,1 & 16,0 & 16,0 \\
\hline Grécia & 10,1 & 11,8 & 11,7 & 11,9 & 11,3 & 13,1 & 13,9 & 13,0 & 13,0 & 13,0 \\
\hline Holanda & 10,6 & 10,4 & 10,4 & 11,8 & 11,4 & 11,6 & 10,9 & 10,1 & 10,2 & 10,2 \\
\hline Hungria & 14,7 & 15,4 & 16,1 & 17,0 & 17,5 & 17,0 & 16,6 & 15,8 & 16,0 & 16,0 \\
\hline Irlanda & 18,4 & 17,8 & 18,8 & 18,6 & 18,2 & 18,2 & 18,0 & 17,7 & 13,1 & 13,1 \\
\hline Islândia & 12,7 & 12,8 & 13,1 & 12,9 & 13,8 & 13,4 & 13,5 & 13,2 & 13,6 & 14,2 \\
\hline Itália & 16,0 & 16,8 & 16,7 & 16,5 & 17,3 & 17,2 & 17,5 & 17,9 & 17,9 & 17,9 \\
\hline Japão & 13,9 & 14,7 & 14,8 & 14,0 & 14,6 & 14,3 & 14,4 & 14,9 & 13,7 & 13,7 \\
\hline Luxemburgo & 16,6 & 16,6 & 15,7 & 15,5 & 17,4 & 16,5 & 15,9 & 15,5 & 15,0 & 11,9 \\
\hline México & 15,2 & 15,3 & 16,2 & 16,2 & 16,5 & 16,8 & 16,7 & 17,0 & 16,7 & 16,7 \\
\hline Nova Zelândia & 15,6 & 15,8 & 17,0 & 16,7 & 17,3 & 17,7 & 18,1 & 18,0 & 18,3 & 18,3 \\
\hline Noruega & 11,4 & 11,5 & 12,0 & 12,7 & 12,9 & 13,3 & 16,1 & 16,1 & 16,2 & 16,2 \\
\hline Polônia & 9,4 & 9,6 & 10,2 & 9,3 & 9,4 & 9,2 & 9,2 & 10,1 & 10,9 & 10,9 \\
\hline Portugal & 14,9 & 14,2 & 14,7 & 14,7 & 14,6 & 14,5 & 14,6 & 15,4 & 15,4 & 15,4 \\
\hline Reino Unido & 14,3 & 14,5 & 14,7 & 14,8 & 15,2 & 15,3 & 15,7 & 15,6 & 15,1 & 15,1 \\
\hline Suécia & 12,6 & 13,2 & 13,4 & 13,1 & 13,1 & 13,1 & 13,2 & 13,6 & 13,8 & 13,8 \\
\hline Suíça & 16,0 & 17,3 & 17,4 & 18,0 & 18,4 & 18,9 & 19,0 & 19,5 & 19,9 & 20,0 \\
\hline Turquia & 9,8 & 9,5 & 9,1 & 9,7 & 10,8 & 11,3 & 11,9 & 12,1 & 12,8 & 12,8 \\
\hline MÉDIA OCDE & 13,8 & 14,1 & 14,4 & 14,5 & 14,7 & 14,9 & 15,2 & 15,3 & 15,2 & 15,1 \\
\hline
\end{tabular}


Tabela 2 - Percentual do gasto total do governo nos gastos públicos em saúde. OCDE, Mercosul e Brics - 2000-2009 (continuação)

\begin{tabular}{l|r|r|r|r|r|r|r|r|r|r}
\hline MERCOSUL & 2000 & 2001 & 2002 & 2003 & 2004 & 2005 & 2006 & 2007 & 2008 & 2009 \\
\hline Argentina & 14,7 & 14,3 & 15,3 & 14,7 & 15,1 & 14,3 & 14,4 & 13,8 & 13,7 & 14,6 \\
\hline Brasil & 4,1 & 4,7 & 5,0 & 4,4 & 5,1 & 4,7 & 5,1 & 5,4 & 6,0 & 6,1 \\
\hline Paraguai & 17,5 & 15,9 & 14,7 & 14,0 & 14,7 & 13,2 & 11,0 & 11,7 & 12,3 & 12,3 \\
\hline Uruguai & 20,5 & 17,5 & 16,1 & 12,5 & 12,3 & 12,7 & 11,5 & 11,6 & 13,8 & 13,8 \\
\hline Venezuela & 34,6 & 34,0 & 35,6 & 35,5 & 36,2 & 32,5 & 32,4 & 33,7 & 31,4 & 30,8 \\
\hline MÉDIA MERCOSUL & 19,2 & 17,3 & 17,3 & 16,2 & 16,7 & 15,5 & 14,9 & 15,2 & 15,4 & 15,5 \\
\hline
\end{tabular}

BRICS

\begin{tabular}{l|r|r|r|r|r|r|r|r|r|r}
\hline BRASIL & 4,1 & 4,7 & 5,0 & 4,4 & 5,1 & 4,7 & 5,1 & 5,4 & 6,0 & 6,1 \\
\hline China & 10,9 & 9,3 & 9,4 & 9,7 & 10,1 & 9,9 & 9,9 & 10,3 & 10,3 & 10,3 \\
\hline Índia & 3,9 & 4,0 & 3,5 & 3,4 & 2,9 & 3,2 & 3,9 & 4,1 & 4,4 & 4,1 \\
\hline Rússia & 12,7 & 12,4 & 11,2 & 11,0 & 11,3 & 11,7 & 10,8 & 10,2 & 9,2 & 8,5 \\
\hline MÉDIA BRICS & 7,9 & 7,6 & 7,3 & 7,1 & 7,4 & 7,4 & 7,4 & 7,5 & 7,5 & 7,3 \\
\hline
\end{tabular}

Fonte: GIS/Ensp/Fiocruz, com base em dados da WH0, 2010.

\section{DESAFIOS E OPORTUNIDADES ASSOCIADOS ÀS MUDANÇAS NOS PADRÕES DE DEMANDA MUNDIAL E NACIONAL}

As informações apresentadas nas tabelas anteriores também revelam a dimensão da área da saúde nas economias nacionais, a qual mobiliza parte expressiva da demanda mundial, dos países e regiões. Além disso, o perfil de saúde da população mundial (o perfil epidemiológico) passa por um processo importante de transformação, em decorrência tanto de fatores demográficos quanto de fatores econômicos e sociais que interferem indiretamente e talvez de forma mais importante nos indicadores de saúde comparativamente às ações de saúde em sentido estrito (Comission on Social Determinants of Health, 2008). Como resultado, os países desenvolvidos passaram por um processo de progressivo e significativo aumento na expectativa de vida, redução dos indicadores de mortalidade e mudança no perfil da demanda em saúde: elevouse o peso das doenças crônico-degenerativas (a exemplo das decorrentes do sistema circulatório e do câncer) e reduziram-se progressivamente as doenças infecciosas e parasitárias, entre muitas outras mudanças em nível maior de desagregação nos tipos de doenças (WHO, 2012b). 
O fator relevante para este estudo é que, além do peso e do incremento esperado na demanda sobre o CEIS, há um processo de transformação muito intenso, também influenciado por novas práticas assistenciais e decorrentes das novas tecnologias, que geram novas e diferenciadas demandas.

Ao tratar de mercado para a saúde no Brasil, destacamos duas importantes dimensões, sem prejuízo de outras já mencionadas e que ainda serão exploradas nos próximos capítulos: a demografia e a epidemiologia, que pesam sobremaneira no surgimento e transformação de necessidades de saúde e, portanto, devem alterar os padrões de demanda, exercendo forte impacto sobre a configuração do sistema produtivo.

Do ponto de vista demográfico e epidemiológico, verificam-se no país o progressivo aumento da expectativa de vida e o consequente envelhecimento da população. Acompanham esse processo mudanças no quadro de morbimortalidade, que se torna mais complexo e sobre o qual as doenças agudas e de origem infecciosa apresentam incidências decrescentes, com aumento constante e consistente da prevalência de doenças crônico-degenerativas, embora não no nível observado nos países desenvolvidos. Há, de fato, um mosaico epidemiológico que se relaciona ao quadro de heterogeneidade e desigualdade social e territorial vigente no Brasil.

Esse cenário fortalece a conviç̧ão de que novos modelos de atenção implicarão alto dinamismo e grande transformação nas condições de demanda, exercendo pressão sobre o sistema industrial (novas vacinas, medicamentos, equipamentos) e sobre a produção de serviços hospitalares, ambulatoriais e de diagnóstico, com elevação do peso destes dois últimos setores na área de serviços. A medicina, perante esses novos problemas de saúde, marcadamente no que tange às doenças crônico-degenerativas, em muitos casos (como no diabetes e na hipertensão) não oferece a cura, mas aumenta muito a possibilidade de se deter a evolução natural desses males, o que se desdobra em forte pressão sobre os gastos e sobre a demanda do CEIS.

Neste novo contexto, conforme apresentado no Gráfico 1, identifica-se uma clara alteração nas taxas de mortalidade e natalidade, com impacto sobre a configuração da estrutura populacional. No Brasil, ao contrário do observado em países mais avançados, onde esse processo de transição demográfica remonta ao século XIX, tal movimento só ocorreu mais recentemente, encontrando-se ainda em curso.

Observadas as tendências, verifica-se que a estrutura da população brasileira irá se alterar de modo significativo nas próximas décadas, com expressivo crescimento da população mais idosa e diminuição relativa da população de menor idade, o que corresponde à diminuição da base da pirâmide populacional brasileira já prevista para a próxima década e bastante nítida na projeção para 2020 e 2050 (Gráficos 2). A alteração da estrutura populacional exerce forte impacto sobre as necessidades de saúde, acarretando uma forte e esperada demanda por bens e serviços concentrada em faixas etárias mais elevadas. 0 envelhecimento populacional marcará sobremaneira as próximas décadas do sistema de saúde brasileiro, que ganhará contornos dramáticos se não forem superadas as limitações do Estado para enfrentar essa nova realidade. 
Gráfico 1 - População residente, mortalidade e natalidade. Brasil - 1940-2009

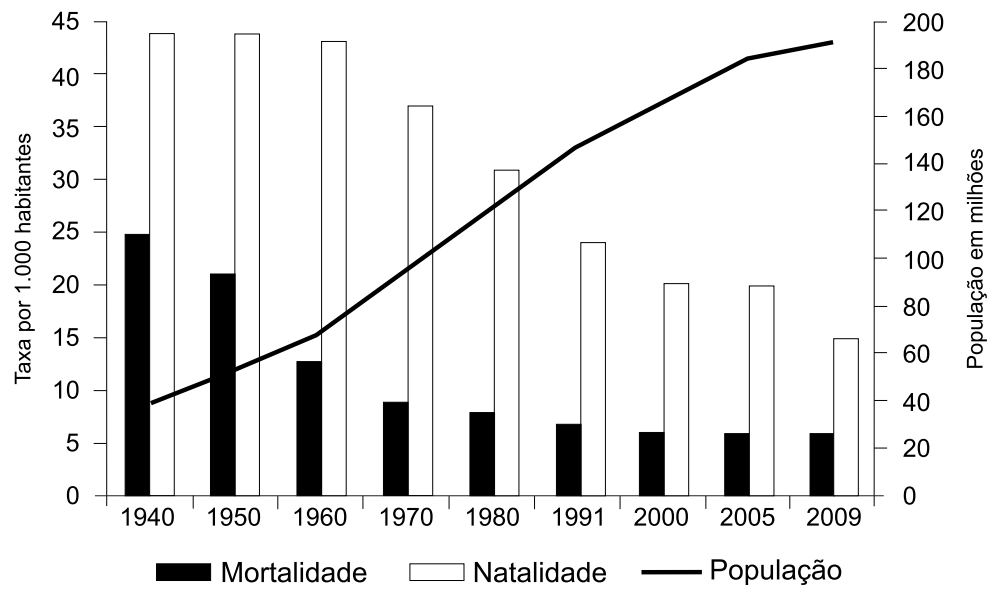

Fonte: GIS/Ensp/Fiocruz, 2012, com base em dados do IBGE, 2007b, 2009a.

Gráficos 2 - Pirâmides etárias absolutas. Brasil - 2010, 2020 e 2050

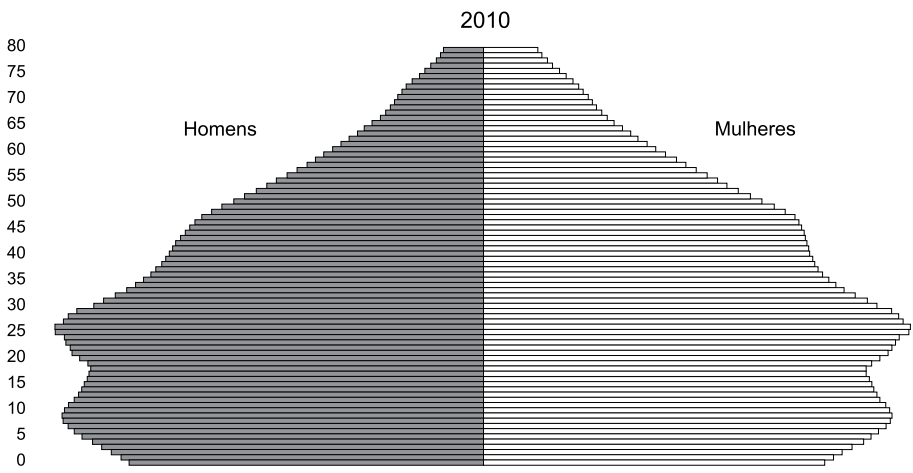

2020

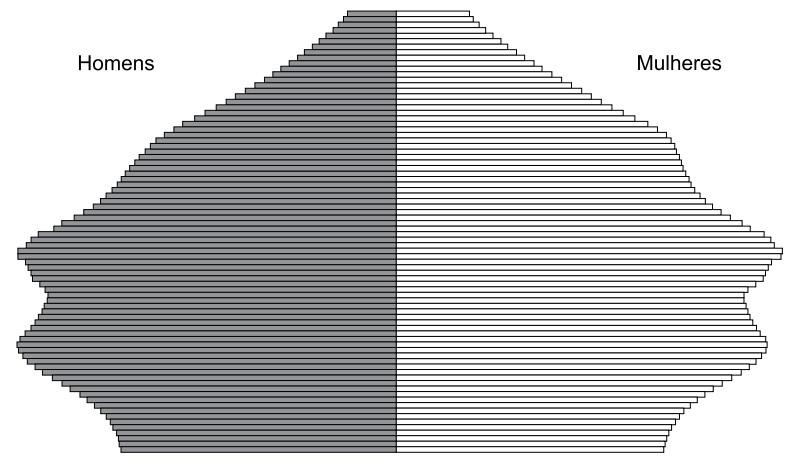


Gráficos 2 - Pirâmides etárias absolutas. Brasil - 2010, 2020 e 2050 ( continuação )

2050

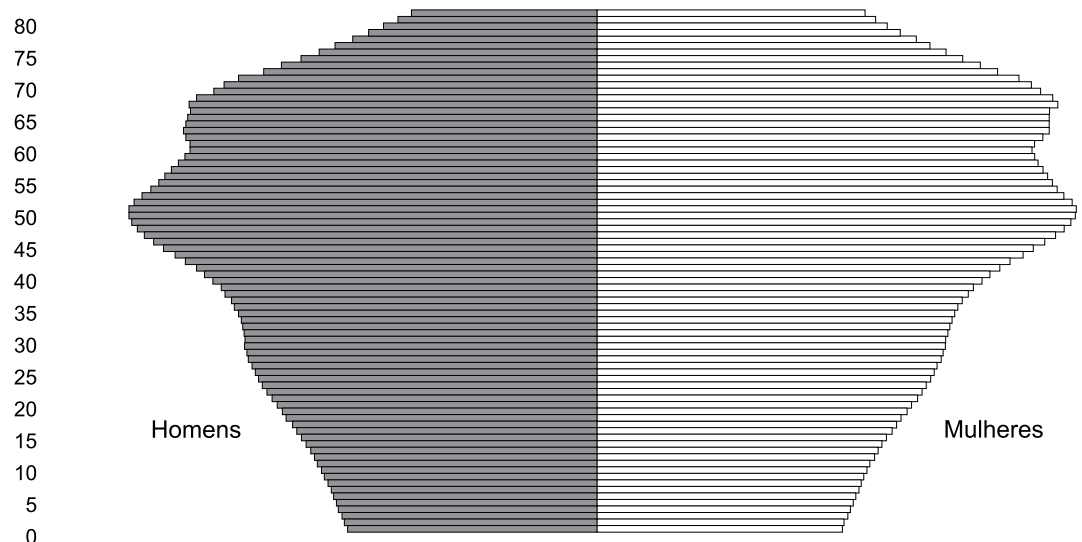

Fonte: GIS/Ensp/Fiocruz, 2011, com base em dados do IBGE, 2010a.

o Gráfico 3 destaca em particular o crescimento populacional da faixa etária superior a 80 anos, demonstrando de forma contundente o seu peso relativo e, consequentemente, o que deverá expressar em demandas para o CEIS. As condições atuais apontam para importante limitação em termos de garantias de que a expectativa de vida crescente em muitos países seja acompanhada de qualidade de vida. Estudos recentes da Organização Mundial da Saúde e do Programa das Nações Unidas para o Desenvolvimento (Pnud) trazem à tona uma realidade pouco conhecida e explorada, denotando limitações em muitas sociedades para garantir qualidade de vida de forma associada à elevação da expectativa de vida. A Tabela 3 apresenta o Brasil em situação desfavorável em anos de vida saudáveis perdidos, em comparação com diversos outros países. Esse indicador expressa, muito certamente, a presença de acometimentos de natureza crônica na saúde dos indivíduos, condição esperada em grupos de idades mais elevadas, mas que se torna mais crítica quando estes não vivem em condições sociais adequadas e, naturalmente, também dependem dos bens e serviços de saúde.

Aos indicadores clássicos de morbidade e mortalidade, acrescentam-se outros capazes de aferir o peso relativo de determinada doença em termos de anos de vida perdidos (em relação à expectativa de vida na referida população) ajustados por incapacidades, isto é, morbidades e respectivas sequelas que comprometam a qualidade de vida dos indivíduos, o que determina o perfil de demanda ao sistema produtivo. Estudo pioneiro e ainda único para o país apurou a carga de enfermidade com base em DALYs, Disability Adjusted Life Years ou anos de vida perdidos ajustados por incapacidades (Schram et al., 2004). A perda de anos vividos com qualidade em determinada doença é, portanto, incorporada à respectiva carga. 
Gráfico 3 - População de 80 anos ou mais de idade por sexo. Brasil - 1980-2050

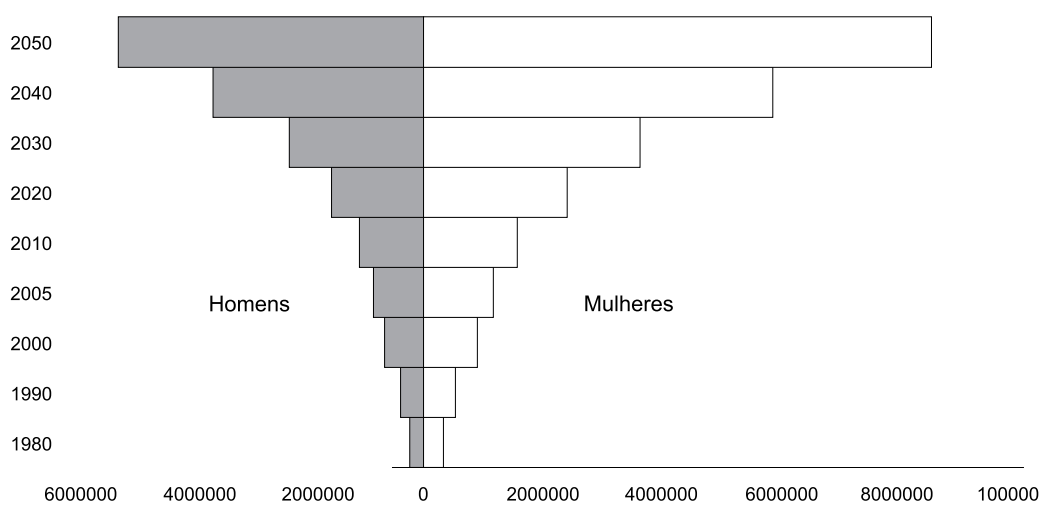

Fonte: GIS/Ensp/Fiocruz, 2012, com base em dados do IBGE, 2010a.

Tabela 3 - Perda de anos de vida saudáveis por sexo. Diversos países - 2003

\begin{tabular}{l|c|c}
\hline PAís & HOMENS & MULHERES \\
\hline Finlândia & 8,0 & 6,6 \\
\hline EUA & 9,4 & 8,2 \\
\hline Alemanha & 7,8 & 6,2 \\
\hline Argentina & 10,6 & 9,1 \\
\hline México & 10,1 & 10,1 \\
\hline Rússia & 8,1 & 5,6 \\
\hline Brasil & 13,5 & 11,1 \\
\hline China & 9,3 & 8,0 \\
\hline África do Sul & 7,0 & 6,5 \\
\hline Índia & 11,3 & 9,3 \\
\hline
\end{tabular}

Fonte: Ipea, 2008.

Essa medida permite aferir mais adequadamente as importâncias relativas das doenças para o CEIS e desenvolver estratégias públicas e empresariais para a saúde, selecionando-se prioridades em uma perspectiva de médio e longo prazos. As Tabelas 4 e 5 apresentam dados da carga da enfermidade para grupos de doenças e para as principais doenças, destacando-se a tendência ao aumento do peso das doenças crônico-degenerativas. 
A dinâmica dos serviços de saúde, como do conjunto do CEIS, sempre sofrerá influência de aspectos demográficos e epidemiológicos de determinada população, acompanhada por outras variáveis econômico-sociais. Mas o propósito deste breve esforço de situar o tema, longe de esgotá-lo, é valorizar dimensões pouco comuns em estudos com propósitos fundamentalmente econômicos. A importância aumenta ainda mais quando se propõe em estudos econômicos que a saúde e a prestação de serviços no país devem ser tratadas como política de Estado, constitucionalmente estabelecida. A dinâmica do investimento não deve, portanto, apartar-se dessas considerações, mas, ao contrário, assumir os vetores demográficos e epidemiológicos como importantes condicionamentos para os investimentos.

Em síntese, o padrão de demanda internacional e mais fortemente o do mercado nacional estão em processo intenso de transformação. No Brasil, esse padrão de demanda se transforma pela adoção tardia de uma estratégia política para organizar um sistema universal, pela mudança no padrão demográfico e epidemiológico, pelas mudanças nas práticas assistenciais e também pela alteração nas condições sociais no sentido de uma melhor distribuição de renda e da diminuição do nível de pobreza (IBGE, 2009b).

Nesse contexto da demanda em saúde, o Brasil apresenta grandes oportunidades de mercado, porque todos os fatores indicados anteriormente apontam tanto para um crescimento substantivo, não reversível e a longo prazo, da demanda para o CEIS quanto para a abertura de novos segmentos de mercado ainda não explorados em toda a sua potencialidade no contexto nacional. Todavia, essa situação também revela riscos na medida em que o processo de transformação aproxima o Brasil do padrão de demanda vigente nos países desenvolvidos que já possuem uma base produtiva sólida de bens e serviços de saúde. No momento atual, de economia crescentemente globalizada, se as estratégias pública e privada nacionais não monitorarem o contexto em mutação e a ele se anteciparem, a base produtiva nacional pode ter seu desenvolvimento obstaculizado por sua falta de competitividade internacional.

Tabela 4 - Carga da enfermidade por grandes grupos. Brasil - 1998 e 2013 (em \%)

\begin{tabular}{l|c|c}
\hline \multirow{2}{*}{ GRUPOS DE ENFERMIDADE } & \multicolumn{2}{|c}{ CARGA } \\
\cline { 2 - 3 } & 1998 & 2013 \\
\hline Doenças infecciosas e parasitárias* & $23,5 \%$ & $17,1 \%$ \\
\hline Doenças crônico-degenerativas & $66,3 \%$ & $74,1 \%$ \\
\hline Causas externas & $10,2 \%$ & $8,8 \%$ \\
\hline
\end{tabular}

* Inclui causas maternas, perinatais e nutricionais.

Fonte: Projeto Carga da Doença no Brasil, 1999. 
Tabela 5 - Carga da enfermidade. Principais doenças. Brasil - 1998 e projeção para 2013

\begin{tabular}{l|c|c|c}
\hline \multirow{2}{*}{ DOENÇA } & \multirow{2}{*}{ CARGA } & \multicolumn{2}{|c}{ RANKING } \\
\cline { 3 - 4 } & 1998 & 1998 & 2013 \\
\hline Diabetes melito & $5,1 \%$ & 1 & 1 \\
\hline Doença isquêmica do coração & $5,0 \%$ & 2 & 2 \\
\hline Doenças cerebrovasculares & $4,6 \%$ & 3 & 3 \\
\hline Transtornos depressivos recorrentes & $3,8 \%$ & 4 & 4 \\
\hline Asfixia e traumatismo ao nascer & $3,8 \%$ & 5 & 14 \\
\hline Doenças pulmonares obstrutivas crônicas & $3,4 \%$ & 6 & 5 \\
\hline Violências & $3,3 \%$ & 7 & 6 \\
\hline Infecções de vias aéreas inferiores & $2,9 \%$ & 8 & 9 \\
\hline Acidentes de trânsito & $2,7 \%$ & 9 & 12 \\
\hline $\begin{array}{l}\text { Demências, Alzheimer, doenças degenerativas, doenças do } \\
\text { sistema nervoso central }\end{array}$ & $2,6 \%$ & 10 & 8 \\
\hline Transtornos mentais/comportamentais por uso de álcool & $2,5 \%$ & 11 & 7 \\
\hline Diarreias & $2,1 \%$ & 12 & 16 \\
\hline
\end{tabular}

Fonte: Projeto Carga da Doença no Brasil, 1999.

\section{DESAFIOS E OPORTUNIDADES ASSOCIADOS ÀS MUDANÇAS TECNOLÓGICAS}

A área da saúde é, claramente, uma das grandes frentes de expansão, distinguindo-se de outras áreas portadoras de futuro em função de sua já significativa participação tanto na base produtiva mundial de bens e serviços quanto nos esforços internacionais de Pesquisa e Desenvolvimento (P\&D). Em termos do CEIS, os elementos mais importantes que devem ser destacados referem-se à crescente interação sistêmica no processo de inovação entre os segmentos produtivos. O esforço de tratamento e prevenção para um grupo de doença específico de alta relevância (como câncer, por exemplo) mobiliza a um só tempo a busca por novos medicamentos de prevenção, como no caso das vacinas quando se evidencia sua relação com agentes infecciosos; a utilização de novos equipamentos eletrônicos para o tratamento e diagnóstico; a introdução de novas práticas assistenciais, em um processo de inovação que envolve, de forma interativa, os serviços médicos, diversos segmentos industriais e a academia.

Ou seja, a saúde se revela como um campo que incorpora grande volume e intensidade de conhecimento e inovação e, principalmente, desenvolve tecnologias estratégicas que exercem impactos interdependentes tanto no CEIS quanto na dinamização 
do tecido econômico-produtivo. Apenas para dar alguns exemplos, que estão longe de englobar as frentes sistêmicas nas áreas de fronteira, podem-se destacar alguns elementos que exercem alto impacto sobre os processos de transformação em curso e articulam diversas áreas do sistema de inovação e do CEIS:

- Novas tecnologias médicas de alta complexidade que mobilizam todo o sistema de inovação (transplante, por exemplo);

- Novas biotecnologias de fronteira;

- Terapia celular, caracterizando a dificuldade de se definir a fronteira entre serviços assistenciais e a biotecnologia industrial;

- Química orgânica avançada (química fina);

- Tecnologia diagnóstica que envolve plataformas tecnológicas para testes de diagnóstico em grande escala, com facilidade e alta precisão.

- Utilização intensiva de Tecnologia da Informação (TI), tanto nos serviços quanto nos equipamentos para diagnóstico e tratamento;

- Nanotecnologia.

Refletindo esse processo de transformação em pleno curso, os esforços mundiais de $P \& D$ em saúde, públicos e privados, talvez só possam ser comparados aos empreendidos no complexo de defesa. O Gráfico 4 e a Tabela 6 mostram o incremento permanente, nos últimos anos, do investimento mundial em P\&D para a saúde em termos nominais e reais. E os Gráficos 5 e 6, que permitem compreender a saúde como uma frente de expansão e transformação tecnológica, evidenciam que o incremento do esforço de $P \& D$ em saúde no mundo cresce bem acima do gasto global com essas atividades: nas últimas duas décadas, a participação percentual do setor se elevou,atingindo em 2005 o patamar de 20\%, correspondente ao valor de US\$ 160 bilhões.

Todavia, esse esforço se distribui no mundo de modo bastante assimétrico, indicando o risco de que se amplie o hiato tecnológico e se acentue a fragilidade do CEIS nas economias de média e baixa rendas e no Brasil em particular. A Tabela 7 mostra que $97 \%$ do gasto global estão concentrados nos países de alta renda, ficando os 3\% para todos os demais países, inclusive o Brasil, o que se expressa nos segmentos industriais do complexo de modo bastante evidente, como será visto nos próximos capítulos. Outra característica que se depreende da leitura dessa tabela é a inversão da participação dos setores público e privado quando se comparam os dois grupos de países. Nos países de alta renda, o setor empresarial responde por cerca de $60 \%$ do dispêndio, enquanto o setor público representa cerca de 40\%, ocorrendo o inverso nos países de baixa e média rendas. No caso dos primeiros, um único deles, os EUA, concentra $50 \%$ do gasto mundial de P\&D em saúde, como mostra 0 Gráfico 7, o que reflete uma concentração marcante na base de geração de conhecimento e de inovação em saúde. 
Gráfico 4 - Estimativa de investimento global em P\&D em saúde - 1998-2005 (em US\$ bilhões)

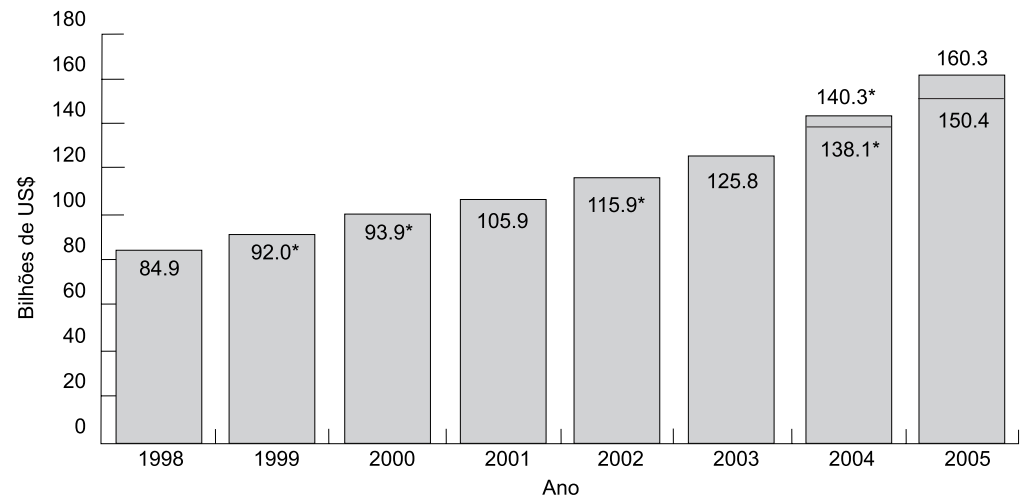

* Valores para 1999, 2000, 2002 e 2004 obtidos por interpolação.

Fonte: Burke \& Matlin, 2008. Estimativa baseada nos relatórios oficiais da OCDE, em inquéritos nacionais, em dados de associações farmacêuticas e em outras publicações.

Tabela 6 - Evolução dos investimentos em P\&D em saúde como proporção do investimento global em P\&D - 1986-2005 (em US\$ milhões de 2000 e \%)

\begin{tabular}{l|r|r|r|r|r|r}
\hline INVESTIMENT0 & \multicolumn{1}{|c|}{1986} & \multicolumn{1}{|c|}{1992} & \multicolumn{1}{|c|}{1998} & \multicolumn{1}{c|}{2001} & 2003 & 2005 \\
\hline P\&D total, ajustado pela inflação & 365.1 & 451.3 & 527.1 & 610.6 & 623.7 & 664.4 \\
\hline P\&D em saúde, ajustado pela inflação & 42.0 & 64.0 & 87.5 & 103.6 & 118.0 & 143.7 \\
\hline Participação da P\&D em saúde em relação à P\&D total (\%) & 11.5 & 14.2 & 16.6 & 17.0 & 19.0 & 21.6 \\
\hline
\end{tabular}

Fonte: Burke \& Matlin, 2008.

Gráfico 5 - Evolução da participação dos investimentos em P\&D em saúde, comparada com o investimento global em P\&D - 1986-2005

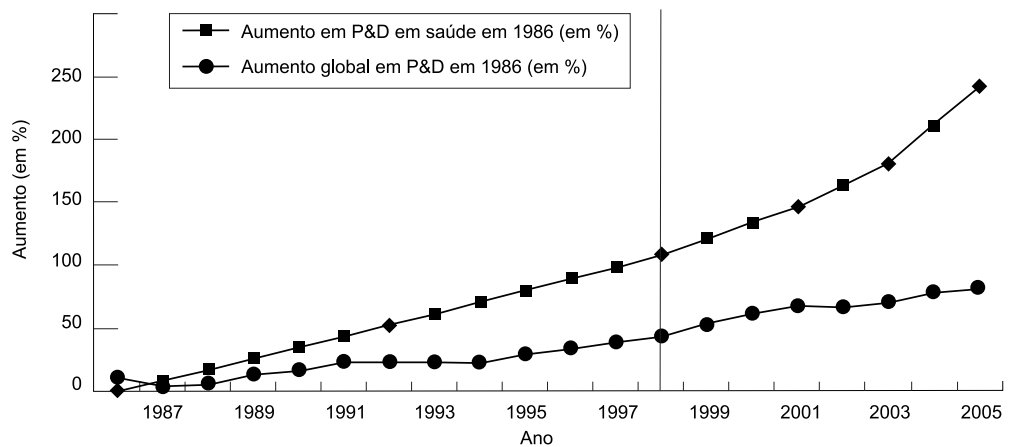

Fonte: Burke \& Matlin, 2008. 
Gráfico 6 - Investimentos em P\&D em saúde como proporção do investimento global em P\&D $-1986-2005$

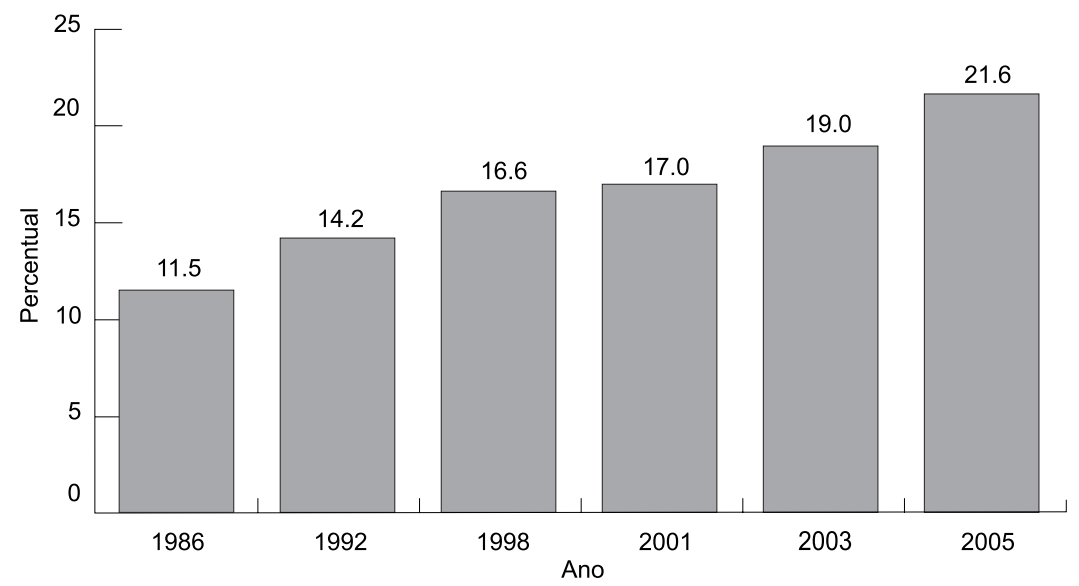

Fonte: Burke \& Matlin, 2008.

Essa situação talvez represente o maior desafio para o desenvolvimento do CEIS no Brasil, visto que esse sistema produtivo é claramente intensivo em conhecimento e inovação e baseado na ciência. Os dados da IBGE (2010b) apresentados nos dois capítulos seguintes refletem o baixo comprometimento do setor empresarial com as atividades de $P \& D$, em que pese o fato de a inovação estar na agenda estratégica de todos os segmentos do CEIS e das políticas públicas. Como uma ilustração desse descompasso no sistema produtivo, a Tabela 8 mostra que a área farmacêutica, segundo os dados da Associação da Indústria Farmacêutica Americana, gasta apenas $0,2 \%$ de seu esforço de pesquisa no Brasil, a despeito da presença marcante de empresas americanas no mercado brasileiro, que representa $2 \%$ do mercado mundial, como será visto adiante.

Mesmo com esse reduzido esforço inovativo no CEIS, conforme aferido na Pesquisa de Inovação Tecnológica (Pintec/IBGE) e nos dados apresentados neste capítulo, as atividades realizadas internamente pelo setor produtivo são de baixa densidade de conhecimento. Estão incorporadas nos equipamentos adquiridos ou restritas às fases finais de lançamento de novos produtos e serviços, e muitas vezes se confundem com atividades de marketing ou com as estratégicas de superação das barreiras de regulação sanitária, ou adequação às exigências desta.

Nesse contexto, é preciso construir as oportunidades para a transformação tecnológica tomando-se como ponto de partida a capacidade produtiva instalada no Brasil no CEIS, que certamente é a maior do continente, a despeito de sua baixa intensidade tecnológica, e o fato de o Brasil contar com uma capacitação científica e 
de recursos humanos em saúde bastante significativa. As Tabelas 9 e $10^{5}$ mostram que a área da saúde tem participação relevante e crescente tanto na produção científica de circulação internacional quando no número de doutores, havendo um conjunto de dados do Ministério da Ciência e Tecnologia que revela que essa importância da saúde na ciência brasileira é atestada por praticamente todos os indicadores.

A capacidade produtiva instalada e a capacitação científica e de recursos humanos em saúde significam, por um lado, uma oportunidade para o sistema produtivo, mas, por outro, corroboram a percepção de que a saúde exemplifica o fracasso do modelo linear de inovação, no qual a concepção da transformação produtiva aparecia como um subproduto do esforço científico.

Tabela 7 - Estimativa de investimento global em P\&D em saúde, 2005 comparado a 2003, 2001 e 1998 (em bilhões de dólares correntes)

\begin{tabular}{l|c|c|c|c|c|c|c|c}
\hline \multirow{2}{*}{} & \multicolumn{2}{|c|}{2005} & \multicolumn{2}{c|}{2003} & \multicolumn{2}{c|}{2001} & \multicolumn{2}{c}{1998} \\
\cline { 2 - 10 } & US\$ & $\%$ & US\$ & $\%$ & US\$ & $\%$ & US\$ & $\%$ \\
\hline TOTAL & 160.3 & 100 & 125.8 & 100 & 105.9 & 100 & 84.9 & 100 \\
\hline Total setor público & 66.3 & 41 & 56.1 & 45 & 46.6 & 44 & 38.5 & 45 \\
\hline Total setor privado & 94.0 & 59 & 69.6 & 55 & 59.3 & 56 & 46.4 & 55 \\
\hline $\begin{array}{c}\text { Total privado com } \\
\text { fins lucrativos }\end{array}$ & 81.2 & 81.2 & 51 & 60.6 & 48 & 51.2 & 48 & 40.6 \\
\hline $\begin{array}{c}\text { Total privado sem } \\
\text { fins lucrativos }\end{array}$ & 12.8 & 12.8 & 8 & 9.0 & 7 & 8.1 & 8 & 5.9 \\
\hline
\end{tabular}

\begin{tabular}{|c|c|c|c|c|c|c|c|c|}
\hline PAÍSES DESENVOLVIDOS ${ }^{(b)}$ & & & & & & & & \\
\hline Setor público & 63.3 & 39 & 53.8 & 43 & 44.1 & 42 & 36.2 & 43 \\
\hline Setor privado com fins lucrativos & 79.7 & 50 & 59.3 & 47 & 49.9 & 47 & 40.0 & 47 \\
\hline Farmacêuticas nacionais ${ }^{(c)}$ & 71.0 & 44 & 53.2 & 42 & 44.1 & 42 & 35.0 & 41 \\
\hline Farmacêuticas estrangeiras ${ }^{(c)}$ & 8.7 & 5 & 6.1 & 5 & 5.8 & 5 & 5.0 & 6 \\
\hline Privadas sem fins lucrativos ${ }^{(d)}$ & 12.2 & 8 & 8.6 & 7 & 7.7 & 7 & 5.6 & 7 \\
\hline TOTAL PAÍSES DESENVOLVIDOS & 155.2 & 97 & 121.7 & 97 & 101.6 & 96 & 81.8 & 96 \\
\hline
\end{tabular}

\footnotetext{
${ }^{5}$ A organização da atividade de pesquisa baseada em critérios teórico-metodológicos ou disciplinares é a mais conhecida e mais utilizada até hoje. Todavia, alguns autores têm mostrado que setores de aplicação ou de atividade ganharão crescente importância como forma de organizar a atividade de pesquisa científica e tecnológica (Conass, 2007).
} 
Tabela 7 - Estimativa de investimento global em P\&D em saúde, 2005 comparado a 2003, 2001 e 1998 (em bilhões de dólares correntes) ( continuação )

\begin{tabular}{|c|c|c|c|c|c|c|c|c|}
\hline & \multicolumn{2}{|c|}{2005} & \multicolumn{2}{|c|}{2003} & \multicolumn{2}{|c|}{2001} & \multicolumn{2}{|c|}{1998} \\
\hline & US\$ & $\%$ & US\$ & $\%$ & US\$ & $\%$ & US\$ & $\%$ \\
\hline $\begin{array}{l}\text { Países não desenvolvidos } \\
\text { e em desenvolvimento }{ }^{(\mathrm{e})}\end{array}$ & & & & & & & & \\
\hline Setor público & 3.0 & 1.9 & 2.4 & 1.9 & 2.5 & 2.4 & 2.3 & 2.7 \\
\hline Setor público nacional & 2.3 & 1.4 & 1.9 & 1.5 & 2.0 & 1.9 & 1.8 & 2.1 \\
\hline $\begin{array}{l}\text { Financiamento público } \\
\text { estrangeiro ODA }\end{array}$ & 0.6 & 0.4 & 0.4 & 0.3 & 0.4 & 0.4 & 0.4 & 0.5 \\
\hline $\begin{array}{l}\text { Financiamento público para } \\
\text { pesquisa internacional }\end{array}$ & 0.10 & 0.06 & & 0.06 & 0.07 & 0.07 & 0.07 & 0.08 \\
\hline $\begin{array}{l}\text { Setor privado com fins lucrativos: } \\
\text { farmacêuticas estrangeiras e } \\
\text { nacionais }\end{array}$ & 1.6 & 1.0 & 1.4 & 1.1 & 1.3 & 1.3 & 1.0 & 1.2 \\
\hline $\begin{array}{l}\text { Privadas nacionais sem } \\
\text { fins lucrativos }\end{array}$ & 0.12 & 0.07 & 0.08 & 0.07 & 0.08 & 0.08 & 0.08 & 0.10 \\
\hline $\begin{array}{l}\text { Privadas estrangeiras sem } \\
\text { fins lucrativos }{ }^{(\dagger)}\end{array}$ & 0.4 & 0.3 & 0.3 & 0.2 & 0.3 & 0.3 & 0.2 & 0.3 \\
\hline $\begin{array}{l}\text { Total Países não desenvolvidos e } \\
\text { em desenvolvimento }\end{array}$ & 5.1 & 3.2 & 4.1 & 3.3 & 4.3 & 4.3 & 3.6 & 4.2 \\
\hline
\end{tabular}

(a) Os efeitos nas mudanças de métodos e fontes de dados e resultados para a indústria farmacêutica se refletiram em aumento de US\$10.1 bilhões em 1998.

(b) Países desenvolvidos: Israel 2001, Singapura 2001.

(c) P\&D de farmacêuticas refere-se a investimentos de P\&D fora dos Estados Unidos por empresas-membros da Pharma de propriedade de empresas americanas e $P \& D$ conduzida no estrangeiro por divisões de empresas americanas por empresas não membros da PhRMA. P\&D de farmacêuticas domésticas corresponde às estimativas globais de P\&D das farmacêuticas dos países desenvolvidos menos 0 P\&D de farmacêuticas estrangeiras.

(d) Privadas sem fins lucrativos investiram o estimado em US\$ 3.1 bilhões em fundos de universidades gerais em 2001 e US\$2.5 bilhões em 1998.

(e) Países não desenvolvidos e em desenvolvimento: China (incluindo Taiwan) 2001; Brasil 2001-2003; Chile 2001; Filipinas 2001; Romênia 2001; Federação Russa 2001; Eslovênia 2001; África do Sul 2001-2003; Venezuela 2001.

(f) Pesquisa internacional, Privadas estrangeiras sem fins lucrativos e Assistência de Desenvolvimento Oficial (ODA) são estimativas menos precisas.

Fonte: Burke \& Matlin, 2008. 
Gráfico 7 - Distribuição global de investimentos em P\&D em saúde - 2005

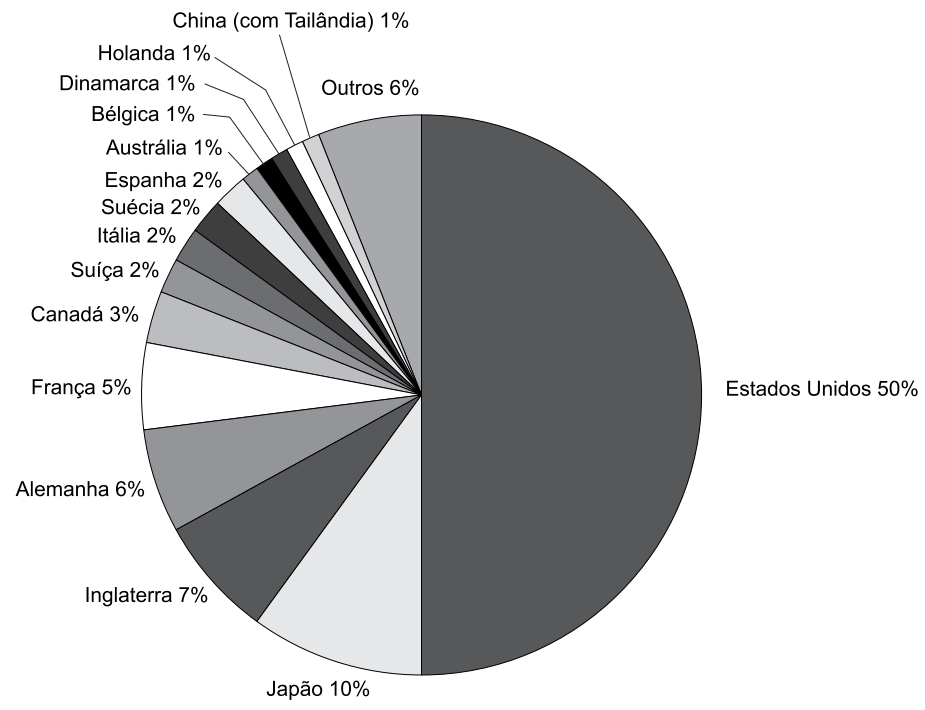

Fonte: Burke \& Matlin, 2008. Estimativa baseada nos relatórios oficiais da OCDE e da Rede de Indicadores de Ciência e Tecnologia (RICYT), em inquéritos nacionais, em dados de associações farmacêuticas e em outras publicações.

Tabela 8 - P\&D por região geográfica, empresas-membros da PhRMA* - 2006 (em US\$ milhões)

\begin{tabular}{|c|c|c|}
\hline ÁREA GEOGRÁFICA & US\$ MLLHÕES & DIVISÃO (\%) \\
\hline África & 25.0 & 0.1 \\
\hline \multicolumn{3}{|l|}{ América } \\
\hline Estados Unidos & 34467.8 & 79.3 \\
\hline Canadá & 528.5 & 1.2 \\
\hline México & 32.2 & 0.1 \\
\hline Brasil & 25.6 & 0.1 \\
\hline Outros países da América Latina \& Caribe & 85.7 & 0.2 \\
\hline \multicolumn{3}{|l|}{ Ásia-Pacífico } \\
\hline Japão & 826.2 & 1.9 \\
\hline China & 32.1 & 0.1 \\
\hline Índia & 8.7 & 0.0 \\
\hline Outros países Ásia-Pacífico & 172.2 & 0.2 \\
\hline Austrália \& Nova Zelândia & 135.2 & 0.3 \\
\hline
\end{tabular}


Tabela 8 - P\&D por região geográfica, empresas-membros da PhRMA* 2006 (em US\$ milhões) (continuação)

\begin{tabular}{|c|c|c|}
\hline ÁREA GEOGRÁFICA & US\$ MLLHÕES & DIVISÃO (\%) \\
\hline \multicolumn{3}{|l|}{ Europa } \\
\hline França & 424.9 & 1.0 \\
\hline Alemanha & 574.2 & 1.3 \\
\hline Itália & 254.9 & 0.6 \\
\hline Espanha & 190.8 & 0.4 \\
\hline Reino Unido & 2280.4 & 5.2 \\
\hline Outros países da Europa Ocidental & 2990.0 & 6.9 \\
\hline Central \& Europa Oriental, incl. Chipre e Malta & 132.2 & 0.3 \\
\hline Federação Russa e novos Estados independentes & 125.1 & 0.3 \\
\hline Meio Leste & 38.9 & 0.1 \\
\hline Não categorizados & 97.4 & 0.2 \\
\hline
\end{tabular}

* Pharmaceutical Research and Manufacturers of America.

Fonte: Burke \& Matlin, 2008.

Tabela 9 - Composição percentual dos artigos completos de circulação internacional ${ }^{1,2}$

\begin{tabular}{|c|c|c|c|c|c|c|}
\hline \multicolumn{7}{|c|}{ PARTICIPAÇÃO NA PRODUÇÃ̃ } \\
\hline $\begin{array}{l}\text { TIPO DE PRODUÇÃO E GRANDE } \\
\text { ÁREA DO CONHECIMENTO }\end{array}$ & $\begin{array}{l}\text { CENSO } 2000 \\
\text { PRODUÇÃO } \\
1997-2000\end{array}$ & $\begin{array}{c}\text { CENSO } 2002 \\
\text { PRODUÇÃO } \\
1998-2001\end{array}$ & $\begin{array}{c}\text { CENSO } 2004 \\
\text { PRODUÇÃO } \\
2000-2003\end{array}$ & $\begin{array}{l}\text { CENSO } 2006 \\
\text { PRODUÇÃO } \\
2003-2006\end{array}$ & $\begin{array}{l}\text { CENSO } 2008 \\
\text { PRODUÇÃO } \\
2005-2008\end{array}$ & $\begin{array}{l}\text { CENSO } 2010 \\
\text { PRODUÇÃO } \\
2007-2010\end{array}$ \\
\hline Ciências Agrárias & $9,1 \%$ & $9,1 \%$ & $9,1 \%$ & $10,0 \%$ & $10,6 \%$ & $11,7 \%$ \\
\hline Ciências Biológicas & $26,0 \%$ & $25,2 \%$ & $23,5 \%$ & $25,2 \%$ & $25,4 \%$ & $25,3 \%$ \\
\hline CIÊNCIAS DA SAÚDE & $13,5 \%$ & $16,2 \%$ & $17,9 \%$ & $22,4 \%$ & $25,4 \%$ & $26,5 \%$ \\
\hline Ciências Exatas e da Terra & $33,4 \%$ & $31,3 \%$ & $29,6 \%$ & $24,5 \%$ & $21,8 \%$ & $19,4 \%$ \\
\hline Ciências Humanas & $2,5 \%$ & $2,7 \%$ & $3,3 \%$ & $2,7 \%$ & $2,7 \%$ & $2,9 \%$ \\
\hline Ciências Sociais Aplicadas & $1,0 \%$ & $1,2 \%$ & $1,8 \%$ & $1,7 \%$ & $1,6 \%$ & $1,7 \%$ \\
\hline $\begin{array}{l}\text { Engenharias e Ciência da } \\
\text { Computação }\end{array}$ & $13,9 \%$ & $13,5 \%$ & $13,9 \%$ & $12,8 \%$ & $12,0 \%$ & $11,9 \%$ \\
\hline
\end{tabular}


Tabela 9 - Composição percentual dos artigos completos de circulação internacional ${ }^{1,2}$ (continuação)

\begin{tabular}{|c|c|c|c|c|c|c|}
\hline \multicolumn{7}{|c|}{ PARTICIPAÇÃO NA PRODUÇÃO } \\
\hline $\begin{array}{l}\text { TIPO DE PRODUÇÃO E GRANDE } \\
\text { ÁREA DO CONHECIMENTO }\end{array}$ & $\begin{array}{l}\text { CENSO } 2000 \\
\text { PRODUÇÃO } \\
1997-2000\end{array}$ & $\begin{array}{c}\text { CENSO } 2002 \\
\text { PRODUÇÃO } \\
1998-2001\end{array}$ & $\begin{array}{c}\text { CENSO } 2004 \\
\text { PRODUÇÃO } \\
2000-2003\end{array}$ & $\begin{array}{l}\text { CENSO } 2006 \\
\text { PRODUÇÃO } \\
2003-2006\end{array}$ & $\begin{array}{c}\text { CENSO } 2008 \\
\text { PRODUÇÃO } \\
2005-2008\end{array}$ & $\begin{array}{l}\text { CENSO } 2010 \\
\text { PRODUÇÃO } \\
2007-2010\end{array}$ \\
\hline Linguística, Letras e Artes & $0,7 \%$ & $0,7 \%$ & $0,9 \%$ & $0,7 \%$ & $0,6 \%$ & $0,5 \%$ \\
\hline SOMA ${ }^{1}$ & $100,0 \%$ & $100,0 \%$ & $100,0 \%$ & $100,0 \%$ & $100,0 \%$ & $100,0 \%$ \\
\hline
\end{tabular}

Elaboração: GIS/Ensp/Fiocruz. Fonte: CNPq/Censo, 2012.

(1) Produção dos pesquisadores doutores informada nos respectivos currículos Lattes (Censo 2000: produção do quadriênio 19972000, informada até 1 jun. 2001; 2002: produção 1998-2001, informada até 12 jul. 2002;2004: produção 2000-2003, informada até 9 dez. 2004;2006: produção 2003-2006, informada até 12 set. 2007;2008: produção 2005-2008, informada até 29 abr. 2009; 2008: produção 2007-2010, informada até 21maio 2011).

Há dupla contagem nos totais obtidos por soma, pois os trabalhos dos pesquisadores que atuam em dois ou mais grupos classificados em grandes áreas predominantes diferentes foram computados uma vez em cada grande área. No âmbito de uma grande área não existe dupla contagem, exceto no caso dos trabalhos publicados em coautoria (um trabalho para cada coautor).

(2) Circulação nacional: idioma = português ou não informado; Circulação internacional: idioma = não português.

A partir de 2008 - Circulação nacional: país da publicação = Brasil ou não informado; Circulação internacional: país da publicação diferente de Brasil.

Tabela 10 - Composição percentual do número de doutores. Brasil - 2000-2010

\begin{tabular}{l|c|c|c|c|c|c}
\hline GRANDE ÁREA & 2000 & 2002 & 2004 & 2006 & 2008 & 2010 \\
\hline Ciências Agrárias & $13,1 \%$ & $13,1 \%$ & $12,4 \%$ & $12,0 \%$ & $11,9 \%$ & $12,0 \%$ \\
\hline Ciências Biológicas & $15,2 \%$ & $15,1 \%$ & $14,3 \%$ & $13,9 \%$ & $13,7 \%$ & $13,4 \%$ \\
\hline CIÊNCIAS DA SAÚDE & $14,6 \%$ & $15,1 \%$ & $15,9 \%$ & $16,6 \%$ & $16,7 \%$ & $16,2 \%$ \\
\hline Ciências Exatas e da Terra & $17,6 \%$ & $15,8 \%$ & $14,6 \%$ & $13,3 \%$ & $12,5 \%$ & $12,2 \%$ \\
\hline Ciências Humanas & $13,1 \%$ & $14,0 \%$ & $14,5 \%$ & $15,7 \%$ & $16,6 \%$ & $17,4 \%$ \\
\hline Ciências Sociais Aplicadas & $6,4 \%$ & $7,3 \%$ & $8,7 \%$ & $9,4 \%$ & $9,6 \%$ & $9,9 \%$ \\
\hline $\begin{array}{l}\text { Engenharias e Ciência da } \\
\text { Computação }\end{array}$ & $16,2 \%$ & $15,5 \%$ & $15,0 \%$ & $14,0 \%$ & $13,6 \%$ & $13,2 \%$ \\
\hline Linguística, Letras e Artes & $3,9 \%$ & $4,1 \%$ & $4,6 \%$ & $5,1 \%$ & $5,4 \%$ & $5,6 \%$ \\
\hline SOMA* & $100,0 \%$ & $100,0 \%$ & $100,0 \%$ & $100,0 \%$ & $100,0 \%$ & $100,0 \%$ \\
\hline
\end{tabular}

* Valores obtidos por soma. Há dupla contagem, tendo em vista que o pesquisador que participa de dois ou mais grupos classificados em grandes áreas predominantes diferentes foi computado uma vez em cada grande área.

Elaboração: GIS/Ensp/Fiocruz. Fonte: CNPq/Censo, 2012. 


\section{DESAFIOS E OPORTUNIDADES ASSOCIADOS ÀS MUDANÇAS NOS PADRÕES DE CONCORRÊNCIA E REGULAÇÃO}

Em decorrência do fato de as mudanças nos padrões de concorrência remeterem necessariamente ao âmbito setorial, sua análise foi concentrada nos capítulos que tratam dos subsistemas com foco nas indústrias-chave. Neste tópico, serão enfatizadas apenas as grandes transformações no CEIS, cuja base de dados e detalhamento será apresentada e explorada posteriormente.

Apesar de seus segmentos produtivos serem relativamente estáveis, uma vez que a mudança tecnológica tende a ocorrer sem alterações profundas nos padrões competitivos vigentes em âmbito internacional, o CEIS vem passando por um processo de profundas transformações. Dentre estas, cabe destacar: a busca por novas fontes de inovação diante do esgotamento das trajetórias percorridas em algumas áreas críticas (como a de medicamentos); a organização global das cadeias produtivas e das bases de P\&D; o enfrentamento e arbitragem diante das condições políticas e sistêmicas de competitividade nacionais e locais.

Dentre as transformações estruturais em curso nos padrões competitivos, destacam-se alguns elementos comuns e interdependentes no CEIS como um todo. Em primeiro lugar, observa-se um processo de concentração no mercado mundial, que tem se acentuado em praticamente todos os segmentos produtivos - da farmacêutica aos planos e seguros de saúde e aos serviços de diagnóstico. Só no último ano, os seguintes exemplos, ainda não trabalhados pela academia por serem muito recentes, evidenciam claramente esse processo:

- A Novartis, depois de adquirir em 2010 a Alcon, empresa especializada na saúde dos olhos, declarou, no fim de 2011, que pretende investir mais de US\$ 3 bilhões em aquisições de ativos no âmbito veterinário ou no segmento de consumo na área de saúde (Valor Econômico, 2011a).

- De acordo com pesquisa realizada pela KPMG Consultoria, as indústrias farmacêuticas globais deverão continuar o movimento de fusões e aquisições (Valor Econômico, 2011d). Essa consolidação também ocorrerá no mercado brasileiro, que está extremamente aquecido. No primeiro semestre de 2011, foram feitas 11 negociações de fusão e aquisição no Brasil, ao passo que ao longo de todo o ano de 2010 houve 18 operações e, em 2009, 12 (Valor Econômico, 2011d).

- O grupo Hypermarcas concluiu em dezembro de 2010 a compra do laboratório brasileiro Mantecorp, tornando-se o maior laboratório nacional em receita. É importante lembrar que essa aquisição é uma das mais recentes de uma política de expansão da Hypermarcas, que vem ocorrendo desde 2009, quando ela comprou a NeoQuímica. Nessa transação ela adquiriu um dos maiores laboratórios especializados em genéricos, em Anápolis (Goiás), desbancando a farmacêutica americana Pfizer. Nesse mesmo local, a Hypermarcas está 
promovendo a incorporação de outras duas empresas farmacêuticas, a DM e a Farmasa. Ademais, a empresa havia comprado em novembro de 2010 três marcas de medicamentos da Medley, controlada pela francesa Sanofi-Aventis (Valor Econômico, 2010a).

- Fica cada vez mais evidente que a biotecnologia em saúde é um negócio para grandes empresas, conforme se depreende dos exemplos a seguir. Em fevereiro de 2011, a farmacêutica francesa Sanofi-Aventis (que já havia adquirido em 2009 a empresa brasileira líder na produção de medicamentos genéricos e terceira maior do setor farmacêutico brasileiro, a Medley) comprou a Genzyme Corp., em uma transação avaliada pela companhia americana de biotecnologia em US\$20.1 bilhões (Valor Econômico, 2011b). A Genzyme é especializada em doenças genéticas raras, e embora não esteja entre as maiores em receita dentro de seu segmento, é uma das mais bem colocadas em P\&D em tratamentos e a quarta maior em biotecnologia no mundo (Reuters, 2010).

- Seguindo essa mesma tendência, em janeiro de 2012 a Roche, a maior fabricante mundial de remédios contra câncer, segmento em que a análise genética está progredindo mais rapidamente, e líder em testes diagnósticos, ofereceu US\$ 5.7 bilhões pela empresa de genética Illumina. O negócio poderá ser o maior que a Roche realiza desde que comprou, por US\$ 47 bilhões, o grupo americano de biotecnologia Genentech, em 2009 (Exame, 2012).

- Também merecem destaque as fusões e aquisições de drogarias no Brasil. Em 2011, Drogasil e Droga Raia se fundiram, tornando-se o sétimo maior grupo varejista do país e líder absoluto do varejo farmacêutico brasileiro. A rede da nova empresa possui mais de setecentas drogarias em nove estados, que representam $78 \%$ do mercado farmacêutico brasileiro $(G 1,2011)$.

- Em 2011, a Brazil Pharma, pertencente ao BTG Pactual, comprou as farmácias Big Ben, Estrela Galdino e Guararapes. Mas a liderança do setor no ano passado ficou com a cadeia resultante da união entre a Drogaria São Paulo e a Pacheco, que fatura $R \$ 4,4$ bilhões e possui 691 lojas, e tirou a liderança da empresa resultante da aliança entre Droga Raia e Drogasil (Brasil Econômico, 2012).

- Alianças estratégicas entre grandes empresas passam a ser estabelecidas, diante de barreiras como a alta dos custos de desenvolvimento de medicamentos e a redução da produtividade. É nesse contexto que, por exemplo, duas grandes companhias farmacêuticas multinacionais, GSK e Johnson \& Johnson, estão unindo forças com a Index Ventures, uma firma de capital de risco, em um fundo de investimentos de $€ 150$ milhões, criado especificamente para acelerar a descoberta de medicamentos. Cada um dos laboratórios farmacêuticos contribuirá com um quarto dos ativos do fundo, ficando o restante a cargo da Index Ventures, que usará sua abordagem de "investimento centrado em ativos" para dar suporte a medicamentos experimentais, em vez investir em companhias iniciantes (Reuters, 2011). 
- No campo dos equipamentos, o mesmo processo de concentração é observado internacionalmente, havendo, inclusive, exemplos de aquisições por parte de farmacêuticas. A Johnson \& Johnson anunciou em abril de 2011 que compraria a fabricante de equipamentos médicos Synthes por 21.6 bilhões de dólares em sua maior aquisição até agora. A operação tem como foco reforçar os negócios da companhia na área ortopédica e pode mudar o setor (Reuters, 2011).

- Em 2009, a empresa nacional líder na produção de medicamentos genéricos e a terceira maior do setor farmacêutico, a Medley, foi adquirida pelo grupo SanofiAventis por $\mathrm{R} \$ 1,5$ bilhão, tornando-se, assim, o maior produtor de genéricos da América Latina e colocando, novamente, o risco de desnacionalização da indústria no patamar das décadas passadas.

- A empresa americana de biotecnologia Amgen fechou em abril de 2011 aquisição do laboratório brasileiro Bergamo, que desenvolve medicamentos com foco em doenças graves. Segundo o vice-presidente da Amgen para Ásia e América Latina, Richard Davies, o foco da americana no país serão o segmento oncológico e o setor hospitalar governamental. $O$ valor da transação totalizou US\$ 215 milhões e envolve a unidade produtiva da brasileira em Taboão da Serra, SP. Outra consequência da aquisição é que a Amgen deve recuperar os direitos sobre seus produtos que haviam sido cedidos à Mantercorp, recentemente comprada pela Hypermarcas (Valor Econômico, 2011c).

- Nos serviços, o maior grupo de medicina diagnóstica instalado no Brasil, o Diagnóstico da América (Dasa), adota uma política agressiva de compra de empresas menores; tal movimento é perceptível no intenso processo de fusões, aquisições e acordos diversos entre operadoras de planos e seguros de saúde, hospitais, serviços de diagnóstico e mesmo articulação entre prestadores de serviços e indústrias do CEIS.

- Esse movimento pode ser observado também no Subsistema de Serviços. Podese citar como exemplo a compra do controle do Hospital São Luiz por parte do banco BTG Pactual, por intermédio da Rede D’Or, em setembro de 2010. Com essa operação, a carioca D'Or consolida ainda mais sua posição de maior grupo hospitalar do país, com faturamento de $\mathrm{R} \$ 2,3$ bilhões (Valor Econômico, 2010).

- Outro exemplo é a incorporação da holding de laboratórios MD1 Diagnósticos, controlada por Edson Godoy Bueno, maior acionista da Amil, pelo Dasa. Quando concluída a transação, o Dasa crescerá significativamente, tornando-se líder de mercado no Rio de Janeiro, onde os laboratórios da MD1 têm presença relevante (Reis, Landim \& Pieroni, 2011; Saúde Web, 2011a). É válido ressaltar que a Amil fez uma aquisição da Medial no final de 2009, o que ilustra claramente os processos de concentração e diversificação aqui relatados.

- De forma análoga, o Fleury, principal concorrente da rede de laboratórios anteriormente citada, amplia suas participações a partir de julho de 2011, com a 
aquisição da rede de laboratórios Cardiolab, do grupo Labs D'Or. O Fleury não tinha a presença nacional do Dasa e tem entre seus acionistas o Bradesco, que concorre com a Amil no segmento de planos de saúde (Saúde Web, 2011b).

- As TIs invadem irreversivelmente a área da saúde. Veja-se a entrada da Intel na área da saúde em hardware e software, que passa, claramente, a constituir um sistema produtivo central nas TIs, inclusive como espaço de geração de inovações extremamente dinâmico, que permite explorar uma futura convergência das tecnologias de base microeletrônica e biotecnológica, abarcando e integrando desde a informatização dos prontuários médicos até os avanços em biologia molecular no campo da genômica e da proteômica.

Esse movimento, captado na leitura de diversos dados apresentados adiante, tem três significados importantes na dinâmica competitiva. Primeiro, permite descartar a hipótese de que os segmentos intensivos em tecnologia do CEIS serão ou podem ser espaços competitivos para pequenas empresas de base tecnológica que não se associem ou estabeleçam parcerias para superar as barreiras econômicas, tecnológicas e regulatórias vigentes no mercado global. Segundo, mostra que as empresas líderes estão voltadas para aproveitar as oportunidades que se abrem em economias emergentes que apresentam potencial de crescimento sustentado, a exemplo do Brics, mas cuja estratégia tecnológica é bastante fechada, restrita e dependente de forte indução das economias nacionais. Terceiro, é possível também entender que o sistema produtivo da saúde está se tornando um espaço competitivo mais orgânico, em que os distintos segmentos produtivos que convergem para um mesmo ambiente institucional e regulatório são interdependentes.

Nesse contexto, somente países com estratégias agressivas de produção e de inovação voltadas para o fortalecimento de empresas nacionais mesmo quando em parceria com grande players do mercado, como a Índia e a China, estão conseguindo participar da dinâmica industrial global de modo ativo, sustentado e competitivo.

Para o Brasil, a despeito de se constituir um mercado mundial importante em todos os segmentos do CEIS, essa situação traz o risco de aumentar o hiato em relação à fronteira tecnológica mundial. A estrutura produtiva brasileira ainda se mostra bastante frágil, inclusive em termos da gestão corporativa, para enfrentar uma concorrência global mais acirrada e com atores de grande peso atualmente também voltados para os mercados emergentes.

Algumas das principais questões relativas à atuação competitiva dos segmentos produtivos do CEIS vinculam-se ao ambiente regulatório. A elevada importância da regulação decorre, conforme analisado no primeiro tópico deste capítulo, do fato de que o ambiente produtivo da saúde está imerso em um campo da política social, visto que a saúde também apresenta características de bem público. Ou seja, a saúde, como um direito a ser protegido e garantido, manifesta-se de forma clara nas políticas regulatórias, sobretudo no campo sanitário (segurança e eficácia da produção em 
saúde), da propriedade intelectual (polarização entre o reforço da apropriação privada dos resultados da inovação e a garantia de acesso dos cidadãos aos bens em saúde) e na política de incorporação tecnológica dos novos produtos e procedimentos nos sistemas nacionais: o peso público no mercado da inovação em saúde obriga o Estado a analisar a custo-efetividade dos novos produtos para aceitar sua incorporação nas práticas e no sistema de saúde, mesmo nos sistemas universais mais avançados.

O jogo regulatório constitui, assim, uma das principais formas de gerar barreiras à entrada nos mercados do CEIS, o que explica em grande parte a dificuldade competitiva de empresas de menor porte. Em outra perspectiva, a preparação para se articular com o ambiente regulatório também pode se constituir em parte essencial das estratégias públicas e privadas de desenvolvimento do CEIS nos Estados nacionais e no Brasil, em particular.

Por fim, apesar desse contexto internacional tornado mais difícil pelas transformações competitivas e do ambiente regulatório, o Brasil apresenta oportunidades competitivas para o desenvolvimento do CEIS, a saber:

- Dimensão do mercado nacional e do mercado público, com tendência de crescimento sustentável em função do crescimento da demanda pelos motivos explicitados neste capítulo.

- Condições produtivas favoráveis decorrentes da existência de um parque de bens industriais e de serviços instalado no país.

- Ambiente político favorável, decorrente da retomada de uma visão de que cabe ao Estado implementar políticas desenvolvimentistas na área da saúde.

- Ambiente regulatório relativamente organizado e pressionado para atender às estratégias de adensamento do sistema produtivo e de inovação em saúde.

- Base científica relativamente avançada no campo da saúde, em termos de grupos e linhas de pesquisa, do gasto público, da disponibilidade de doutores e da força de instituições científicas que atuam no campo da saúde, entre diversos outros indicadores (Guimarães, 2004b, 2004a). 